\title{
Use of Topical Ozone Therapy for Wound Healing after Transalveolar Extractions: A Miracle Alternative Therapy
}

\author{
Devyani Bahl $^{1}$, Soumi Samuel ${ }^{2}$, R Narayana Charyulü $^{3}$, Sudhir Dole ${ }^{4}$
}

\begin{abstract}
Aim: To evaluate the effect of topical ozone therapy for wound healing after transalveolar extractions.

Materials and methods: A prospective study was conducted on 72 patients who underwent transalveolar extraction procedure and were divided into 2 groups-Ozone group and the control group with 36 patients in each group. After the procedure, the patients in the ozone group, received ozonated oil and the control group received normal saline irrigation. The ozone group patients were prescribed to apply the Ozonated oil locally at the extraction site for 3 times daily for a period of 5 days. Antibiotics were not prescribed in the ozone group but were given for the control group. Analgesics were given on SOS basis in the ozone group and for 5 days in the control group. The subjects were evaluated for postoperative wound healing, pain and swelling on the 3rd and 7th day. The final POSSE score and the number of analgesics taken were recorded on the 7th day.

Results: Patients in the ozone group had better wound healing on POD3 and POD7 when compared to the control group. There were decreased VAS pain, and swelling scores in the ozone group compared to the control group with statistically significant difference $(p<0.001)$. The patients in the ozone group took lesser analgesics than the control group. Overall post-extraction discomfort was significantly lesser in the ozone group when compared to the control group $(p<0.001)$.

Conclusion: With the present study results, we can say that the topical ozone therapy can be used as an effective treatment modality for accelerating healing and reducing the pain after transalveolar dental extractions.

Clinical significance: Dental extraction, though routinely done procedure in the clinical setting, has various postoperative complications, pain and swelling being the most common. Hence, ozone therapy can be used as an effective topical agent to manage post-extraction pain and swelling in healthy patients without the need for excess medications.

Keywords: Ozone therapy, Pain, Randomised control trial, Transalveolar extraction, Wound healing.

World Journal of Dentistry (2022): 10.5005/jp-journals-10015-1888
\end{abstract}

\section{INTRODUCTION}

Ozone is a natural gas molecule that is chemically composed of three oxygen atoms.

Ozone therapy is a multifaceted bio-oxidative therapy wherein the ozone is administered as a gas or dissolved in water or oil base to provide therapeutic outcomes. ${ }^{1}$

With the development of medical grade ozone, its use has been greatly increased as an adjunct to the treatment of various lesions and as a sole mode of treatment in certain specific clinical conditions. Many disease states such as long-standing non-healing ulcers, ${ }^{2}$ circulatory disorders, ${ }^{3}$ infections, ${ }^{4}$ burns, and skin lesions ${ }^{2}$ have had beneficial healing effects after application of ozone therapy.

The various therapeutic applications of topical ozone therapy can be attributed to its pharmacological actions such as microbicidal activity, ${ }^{3}$ promotion of vascularity ${ }_{1}^{5}$ and immunostimulation. ${ }^{4}$ E.A. Fisch pioneered the use of ozone therapy in dental practice in the 1930 's, to aid in disinfection and wound healing during dental surgeries. $^{6}$

\section{Properties of Ozone}

A colorless gas, ozone has a striking pungent odor at room temperature, which can be detected in concentrations as low as $0.02-0.05 \mathrm{ppm}^{7}$ Its half-life varies with temperature variation. At $20^{\circ} \mathrm{C}$, it has a half-life of 40 minutes and at $0^{\circ} \mathrm{C}$ about 140 minutes. $^{8}$
1,2Department of Oral and Maxillofacial Surgery, AB Shetty Memorial Institute of Dental Sciences (ABSMIDS), NITTE (Deemed to be University), Deralakatte, Mangalore, Karnataka, India

${ }^{3}$ Department of Pharmaceutics, NGSM Institute of Pharmaceutical Sciences, NITTE (Deemed to be University), Karnataka, India

${ }^{4}$ Ozone Dental Clinics, Sector 7, Khargar, Navi Mumbai, Maharashtra India

Corresponding Author: Soumi Samuel, Department of Oral and Maxillofacial Surgery, AB Shetty Memorial Institute of Dental Sciences, NITTE (Deemed to be University), Deralakatte, Mangaluru, Karnataka, India, Phone: +91 9880834711, e-mail: soumisamuel@gmail.com

How to cite this article: BahI D, Samuel S, Charyulu RN, et al. Use of Topical Ozone Therapy for Wound Healing after Transalveolar Extractions: A Miracle Alternative Therapy. World J Dent 2022;13(1):57-61.

Source of support: Nil

Conflict of interest: None

\section{Mode of Application}

Clinically, ozone can be applied in three basic forms, such as gaseous, water, and oil, depending on the medical condition for which it is intended to be used.

Prozone (W and $\mathrm{H}, \mathrm{UK}$, Ltd.) is a new technology that produces ozone in a gaseous state for use in various dental applications. The main advantage of this is that it regulates the flow of concentration of ozone, thereby not exceeding the permitted therapeutic values. ${ }^{9}$ 
Ozonytron device produces an electromagnetic field to transform oxygen into ozone. It then transmits this ozone to the tissue via plasma probes at a maximum concentration of $300,000 \mathrm{ppm}$. Due to the absence of a closed circuit, it is feasible to apply ozone to places that are difficult to reach, such as extraction sockets, gingival pockets, or root canals. ${ }^{10}$

Recently, ozonated oils have been developed in liquid oils, most commonly in virgin olive oil. ${ }^{11}$

Ozone has a wide spectrum of applications due to its unique therapeutic properties. A duration of 10-20 seconds, eliminates $99 \%$ of microflora, as reported in the literature. ${ }^{12}$ It has Antimicrobial effect against bacteria, ${ }^{13,14}$ viruses, ${ }^{4}$ fungi, ${ }^{15}$ yeast, and protozoa. ${ }^{16}$ The antimicrobial activity of ozone increases in the liquid environment, especially in acidic $\mathrm{pH}^{17}$

It also initiates the activation of the immune system by causing a great increase in the production of interferon. ${ }^{18}$ Topical ozone has anti-inflammatory by which it causes the reduction in the release of algogenic chemical mediators and hence acts as a potent analgesic. $^{19}$

A study by Xiao et al. ${ }^{20}$ showed that the application of ozone decreases the wound area and also accelerates wound healing by increasing the migration of fibroblasts. Ozone improves the transportation of oxygen in the blood by raising the $\mathrm{PO}_{2}$ in tissues. ${ }^{21}$

Ahmedi et al. ${ }^{9}$ reported that ozone was more effective than normal saline in reducing the incidence of dry socket and significantly reduced pain after surgical extraction of lower third molars.

Hence, we designed this study to evaluate the efficacy of topical ozone therapy as a potential healing agent post transalveolar extractions.

\section{Materials and Methods}

A prospective study conducted on 72 patients who required surgical extractions (transalveolar extractions) and reported to the Department of Oral and Maxillofacial Surgery, AB Shetty Memorial Institute of Dental Sciences, Mangaluru.

The study was conducted after obtaining institutional ethical clearance and in accordance with the Declaration of Helsinki. Informed written consent was obtained from all patients.

Patients were included based on their willingness to participate in the study, absence of any systemic disease, any tooth indicated for open extraction, and single tooth extractions only. The patients were excluded from the study if they had any associated systemic diseases $\&$ history of allergies, pregnant patients, history of intake of oral contraceptives, patients undergoing orthodontic extractions and mentally challenged patients.

The patients were randomly divided into two groups:

Group I - Ozone group

Group II - Control group

All the included patients underwent the surgical procedure of open extraction. After extraction, the socket was irrigated with saline in the control group and antibiotics and analgesics were prescribed for 5 days to the patients. In the study group, the socket was filled with Ozonated oil.

Post-extraction the patients were advised to put the Ozonated oil at the extraction site three times daily for a period of 5 days. No antibiotics were prescribed in this group. Analgesics were given on SOS basis to the patients.

The patients were followed up on the 3rd and 7th day postoperatively for evaluation of wound healing. They were evaluated base on the post-extraction healing using the Healing index of Landry, Turnbull and Howley. ${ }^{22,23}$ The postoperative discomfort was evaluated using the final POSSE scale on POD7. ${ }^{24}$ Swelling was evaluated giving VAS scores to the patients. Post-extraction pain was evaluated using VAS scale for pain. ${ }^{25}$ The number of analgesic doses (if taken any) were also recorded on POD7. "The descriptive photos are shown in Figure 1."

\section{Preparation of Ozone Gel/Oil}

“Commercially available ozone gel/oil (Ozone Olive Healing Gel manufactured by ADC Inc. Dentozoneindia), which is a natural product composed of suspension of unoxidized olive oil and medical grade ozone, was used."

\section{Statistical Analysis}

The data was recorded and subjected to statistical analysis using Statistical Package for Social Sciences (Version 20). The mean values and standard deviations were calculated for each parameter for the study and control groups. Student's paired $t$-test/Wilcoxon matched pairs was used for comparison between the study and control groups. The value for statistical difference was set at $p<0.05$.
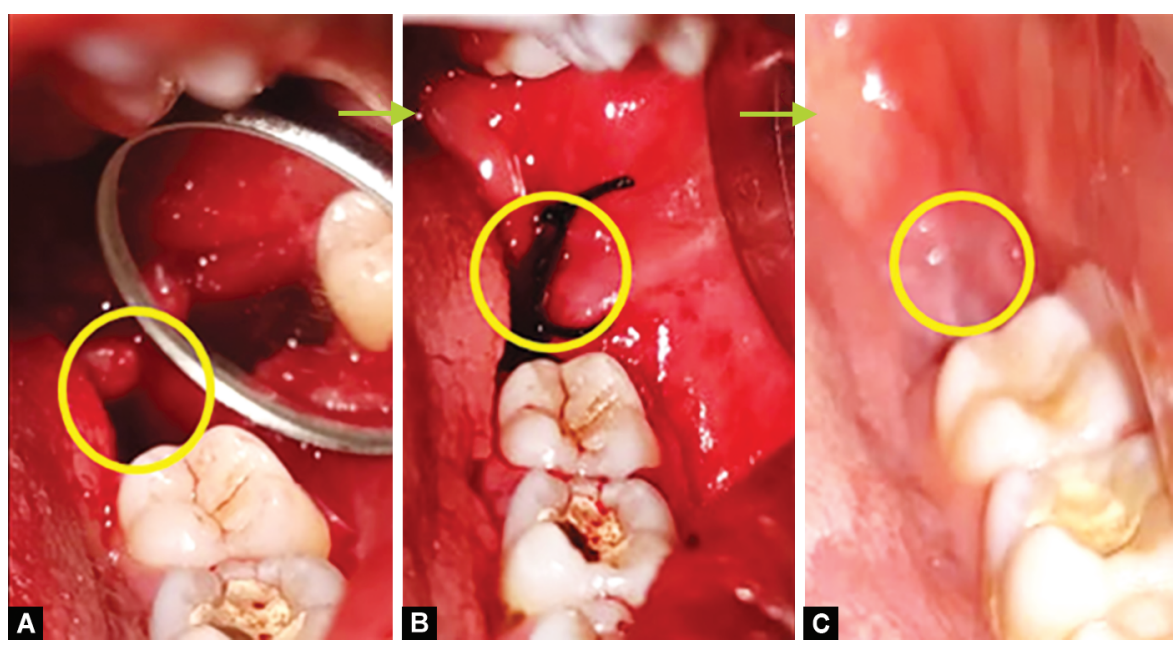

Figs 1 A to C: (A) Post-extraction socket, (B) After ozone application and closure, (C) Postoperative day 7 


\section{Results}

This study was a randomised control trial conducted on 72 patients who underwent transalveolar extractions. The patients were divided into two groups.

Group I - OZONE - 36 patients

Group II - CONTROL - 36 patients.

"In our study, we had a total of 23 males and 49 females. Group I had 9 males and 27 females and group II consisted of 14 males and 22 females (Fig. 1)."

The mean age of patients in the ozone and the control group were 25.19 and 34.14 years respectively.

On comparing the wound healing index between the two groups, it was found that there was statistically significant difference in the scores between the ozone group and the control group on POD3 and POD 7 i.e., $p<0.001$. "This shows that the healing in the ozone group was better when compared to the control group (Table 1)."

The mean pain score on VAS scale on POD3 in the ozone group was $4.00 \pm 0.68$ and in the control, group was $8.39 \pm 0.49$ while on POD7 was reduced to $0.33 \pm 0.48$ in the ozone group and to 2.31 \pm 0.47 in the control group. "There was statistically significant difference $(p<0.001)$ for the scores on POD3 and POD7 (Table 1)."

On assessing the swelling in the study subjects, it was found that there was less incidence of swelling encountered in the ozone group when compared to the control group, both on POD3 and POD7. "The swelling in the ozone group was significantly less than the control group $(p<0.001)$ (Table 1)."

"The mean POSSE score on POD7 in the ozone group was 11.92 \pm 1.27 and in the control group was $28.91 \pm 1.52$ (Fig. 1) and the difference was statistically significant $(p<0.001)$ (Table 2)."
The total number of analgesics taken by the subjects in the ozone group and the control group were 2-4, and 8-10 tablets respectively, when assessed on POD7 (Table 2$)$. There was statistically significant difference $(p<0.001)$.

\section{Discussion}

Tooth extraction is a routine procedure undertaken in the dental OPD. Depending on the depth, location, and angulation of the tooth and the density of the bone, the extractions may often range from being relatively easy to extremely difficult. ${ }^{26}$ Most common complications associated with extractions are excessive pain, swelling, trismus, localized alveolar osteitis, acute osteomyelitis, infection of soft tissues, delayed healing of the socket. ${ }^{27}$ Topical ozone therapy has proved to be effective in accelerating healing post-extraction. It forms a pseudomembrane over the socket and protects it from any further physical or mechanical insults and hence reduces the post-extraction healing time. ${ }^{28}$

During the extraction procedure, the surgical trauma upregulates the biochemical mediators of inflammation and pain such as prostaglandins, bradykinin, histamine, and serotonin. ${ }^{29}$

Generally, the maximum intensity of pain is seen at 3-5 hours post-surgery, which continues for $2-3$ days, and gradually diminishes by the 7 th day. ${ }^{30,31}$

Application of ozone in the socket causes oxidation (inactivation) of metabolic mediators of pain, and hence it acts as a potent analgesic. On topical application, ozone forms a protective layer over the surgical site in the initial postoperative phase. This can lead to the prevention of wound contamination and also covers the exposed nerve endings, ultimately reducing the pain significantly. ${ }^{16}$ This can be justified by the lower VAS pain scores

Table 1: Comparison of parameters between the study groups on day 3 and day 7

\begin{tabular}{|c|c|c|c|c|c|c|c|}
\hline & & \multirow[b]{2}{*}{ Group } & \multirow[b]{2}{*}{$N$} & \multirow[b]{2}{*}{ Mean (SD) } & \multicolumn{2}{|c|}{ Kruskal-Wallis test } & \multirow[b]{2}{*}{ Mann-Whitney U test } \\
\hline & & & & & Chi-square value & $p$-value & \\
\hline \multirow{4}{*}{ WHI } & \multirow{2}{*}{ Day 3} & Ozone & 36 & $3.67(0.48)$ & \multirow{2}{*}{66.09} & \multirow{2}{*}{$<0.001^{\mathrm{a}}$} & \multirow{2}{*}{$<0.001^{\mathrm{a}}$} \\
\hline & & Control & 36 & $2.14(0.35)$ & & & \\
\hline & \multirow{2}{*}{ Day 7} & Ozone & 36 & $5.00(0.00)$ & \multirow{2}{*}{75.65} & \multirow{2}{*}{$<0.001^{a}$} & \multirow{2}{*}{$<0.001^{\mathrm{a}}$} \\
\hline & & Control & 36 & $3.56(0.50)$ & & & \\
\hline \multirow{4}{*}{ VAS pain } & \multirow{2}{*}{ Day 3} & Ozone & 36 & $4.00(0.68)$ & \multirow{2}{*}{95.50} & \multirow{2}{*}{$<0.001^{\mathrm{a}}$} & \multirow{2}{*}{$<0.001^{\mathrm{a}}$} \\
\hline & & Control & 36 & $8.39(0.49)$ & & & \\
\hline & \multirow{2}{*}{ Day 7} & Ozone & 36 & $0.33(0.48)$ & \multirow{2}{*}{77.07} & \multirow{2}{*}{$<0.001^{a}$} & \multirow{2}{*}{$<0.001^{\mathrm{a}}$} \\
\hline & & Control & 36 & $2.31(0.47)$ & & & \\
\hline \multirow{4}{*}{ Swelling } & \multirow{2}{*}{ Day 3} & Ozone & 36 & $0.61(0.49)$ & \multirow{2}{*}{61.42} & \multirow{2}{*}{$<0.001^{\mathrm{a}}$} & \multirow{2}{*}{$<0.001^{\mathrm{a}}$} \\
\hline & & Control & 36 & $1.78(0.42)$ & & & \\
\hline & \multirow{2}{*}{ Day 7} & Ozone & 36 & $0.00(0.00)$ & \multirow{2}{*}{40.43} & \multirow{2}{*}{$<0.001^{\mathrm{a}}$} & \multirow{2}{*}{$<0.001^{\mathrm{a}}$} \\
\hline & & Control & 36 & $0.72(0.45)$ & & & \\
\hline
\end{tabular}

${ }^{a} p<0.05$ statistically significant

Table 2: Comparison of final POSSE scale and analgesic dose between the study groups on day 7

\begin{tabular}{|c|c|c|c|c|c|c|}
\hline & \multirow[b]{2}{*}{ Group } & \multirow[b]{2}{*}{$N$} & \multirow[b]{2}{*}{ Mean (SD) } & \multicolumn{2}{|c|}{ Kruskal-Wallis test } & \multirow[b]{2}{*}{ Mann-Whitney $U$ test } \\
\hline & & & & Chi-square value & $p$-value & \\
\hline \multirow{2}{*}{ Final POSSE scale } & Ozone & 36 & $11.92(1.27)$ & \multirow{2}{*}{96.34} & \multirow{2}{*}{$<0.001^{a}$} & \multirow{2}{*}{$<0.001^{a}$} \\
\hline & Control & 36 & $28.91(1.52)$ & & & \\
\hline \multirow{2}{*}{ Analgesic dose } & Ozone & 36 & $2.94(0.98)$ & \multirow{2}{*}{97.76} & \multirow{2}{*}{$<0.001^{\mathrm{a}}$} & \multirow{2}{*}{$<0.001^{\mathrm{a}}$} \\
\hline & Control & 36 & $9.11(1.01)$ & & & \\
\hline
\end{tabular}

${ }^{a} p<0.05$ statistically significant 
in the ozone group in our study when compared to the control group. It was statistically significant difference $(p<0.001)$ Figure 2 .

The patients in the ozone group also took less number of analgesics postoperatively than those in the control group.

Swelling reaches peak intensity within 12-48 hours, resolving between the 5 th and 7 th days postoperatively. ${ }^{32}$ Ozone decreases the production of mediators of the inflammation and hence can be a potential therapeutic modality for acute inflammation. Studies show that the area of inflammation or infection is acidic (positively charged), and ozone is basic (negatively charged). Hence, the chemistry of inflammation and infection attracts ozone to the area. ${ }^{21}$ In our study we see decreased swelling scores in the ozone group when compared to the control group and the difference was statistically significant $(p<0.001)$.

Kazancioglu et al. ${ }^{10}$ reported the successful use of ozone gas as an extra-oral agent to enhance wound healing following third molar extraction. Our study results are similar to these results as we had better-wound healing in the ozone group compared to the control group.

Our study results are also in accordance with Sivalingam et al. ${ }^{16}$ who administered topical ozone therapy after third molar impaction surgeries. They concluded that topical ozone therapy provides excellent patient comfort as it effectively reduces postoperative swelling, pain, and trismus. Their study also showed a reduced number of analgesic intake by the patients when they received ozone therapy and these results are similar to the results of our study.

\section{Side Effects of Ozone}

In our study, only one patient reported of mild dislike of the taste of the ozonated oil accompanied by nausea. No other side effects were reported.

The use of ozone is contraindicated in myocardial infarction, hyperthyroidism, favism, autoimmune disorders, myasthenia, ozone allergy, and alcohol intoxication. ${ }^{16}$

Though ozone has multiple therapeutic benefits, it also has some infrequent side effects such as epiphora, rhinitis, upper respiratory irritation, headache, occasional nausea and vomiting, and cough.

In the event of an ozone intoxication, the patient must be made to lie down in a supine position, should inhale humid oxygen, and be given ascorbic acid, vitamin $\mathrm{E}$, and $\mathrm{n}$-acetylcysteine. As ozone has high oxidative power, care should be taken to use only ozone resistant materials such as glass, silicon, and Teflon. ${ }^{17}$

\section{Limitations of the Study}

It is a single centre study. To establish the role of ozone in effective wound healing for a larger population, a multicentric study should be conducted.

\section{Conclusion}

Topical ozone therapy has an extensive array of applications in dental surgery, especially due to its remarkable wound healing properties and potent anti-inflammatory and analgesic action. It can be used as an exclusive treatment modality post-dental extractions owing to its immunostimulant, bioenergetic, and biosynthetic, analgesic, antimicrobial and antioxidant, actions. Its atraumatic, non-invasive, and painless nature of the application and the relative absence of discomfort greatly increase the patient's acceptability and compliance with the dental treatment.

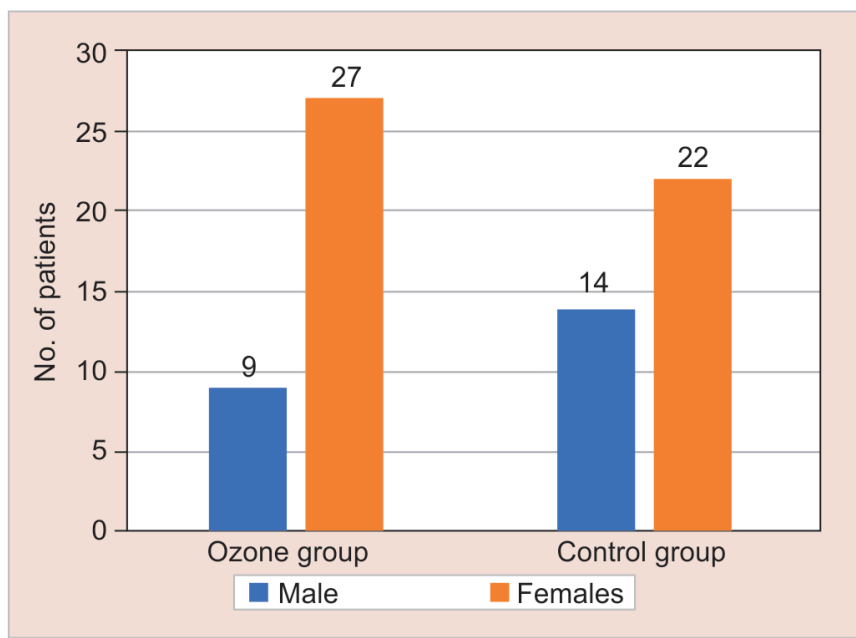

Fig. 2: Gender distribution of study subjects

(Males and females distribution in the ozone and control groups)

\section{Clinical Significance}

Topical ozone therapy can be used as a sole treatment modality for treating patients after an extraction procedure. It may prove to be a viable alternative to postoperative antibiotics and analgesics, eliminating any systemic side effects associated with these.

\section{Manufacturer Detalls}

ADC Inc. Dentozoneindia, Kharghar, Navi Mumbai, Maharashtra 410210, India.

\section{References}

1. Bocci V. Ozone as Janus: this controversial gas can be either toxic or medically useful. Mediators Inflamm 2004;13(1):3-11. DOI: 10.1080/0962935062000197083

2. Travagli V, Zanardi I, Valacchi G, et al. Ozone and ozonated oils in skin diseases: a review. Mediators Inflamm 2010;2010:610418. DOI: 10.1155/2010/610418

3. Seidler V, Linetskiy I, Hubálková $\mathrm{H}$, et al. Ozone and its usage in general medicine and dentistry. A review article. Prague Med Rep 2008;109(1):5-13.

4. Elvis AM, Ekta JS. Ozone therapy: a clinical review. J Nat Sci Biol Med 2011;2(1):66-70. DOI: 10.4103/0976-9668.82319

5. Clavo B, Catalá L, Pérez JL, et al. Ozone therapy on cerebral blood flow: a preliminary report. Evid Based Complement Alternat Med 2004;1(3):315-319. DOI: 10.1093/ecam/neh039

6. Bayson A, Lynch E. Antimicrobial effects of ozone on caries. In: Lynch E, (ed.) Ozone: The Revolution in Dentistry. London: Quintessence Publishing Co. 2004. pp. 165-172.

7. Iliadis D, Millar BJ. Ozone and its use in periodontal treatment. Open J Stomatol 2013;3(2):197-202. DOI: 10.4236/ojst.2013.32034

8. Mandhare MN, Jagdale DM, Gaikwad PL, et al. Miracle of ozone therapy as an alternative medicine. Int J Pharm Chem Biol Sci 2012;2(1):63-71.

9. Ahmedi J, Ahmedi E, Sejfija O, et al. Efficiency of gaseous ozone in reducing the development of dry socket following surgical third molar extraction. Eur J Dent 2016;10: 381-385. DOI: 10.4103/13057456.184168

10. Kazancioglu HO, Kurklu E, Ezirganli S. Effects of ozone therapy on pain, swelling, and trismus following third molar surgery. Int J Oral Maxillofac Surg 2014;43:644. DOI: 10.1016/j.ijom.2013.11.006

11. Uysal B. Ozonated olive oils and the troubles. J Intercult Ethnopharmacol 2014;3(2):49-50. DOI: 10.5455/jice.20140314090801 
12. Reddy SA, Reddy N, Dinapadu S, et al. Role of ozone therapy in minimal intervention dentistry and endodontics - a review. J Int Oral Health 2013;5:102.

13. Mohammadi Z, Shalavi S, Soltani MK, et al. A review of the properties and applications of ozone in endodontics: an update. Iran Endod J 2013;8:40

14. Broadwater WT, Hoehn RC. Sensitivity of three selected bacterial species to ozone. Appl Microbiol 1973;26(3):391-393. DOI: 10.1128/am.26.3.391-393.1973

15. Bocci V. Autohaemotherapy after treatment of blood with ozone. A reappraisal. J Int Med Res 1994;22(3):131-144. DOI: 10.1177/030006059402200301

16. Sivalingam VP, Panneerselvam E, Raja KV, et al. Does topical ozone therapy improve patient comfort after surgical removal of impacted mandibular third molar? A randomized controlled trial. J Oral Maxillofac Surg 2017;75(1):51e1-51e9. DOI: 10.1016/j.joms.2016.09.014.

17. Naik SV, Rajeshwari K, Kohli S, et al. Ozone - a biological therapy in dentistry reality or myth? Open Dent J 2016;10:196-206. DOI: 10.2174/1874210601610010196

18. Werkmeister $\mathrm{H}$. Subatmospheric $\mathrm{O} 2 / \mathrm{O} 3$ treatment of therapy-resistant wounds and ulcerations. OzoNachrichten 1985;4:53-59. DOI: 10.1586/17434440.3.2.175

19. Azuma K, Mori T, Kawamoto K, et al. Anti-inflammatory effects of ozonated water in an experimental mouse model. Biomed Rep 2014;2:671. DOI: 10.3892/br.2014.290

20. Xiao W, Tang H, Wu M, et al. Ozone oil promotes wound healing by increasing the migration of fibroblasts via PI3K/Akt/mTOR signaling pathway. Biosci Rep2017;37(6):BSR20170658.DOI: 10.1042/BSR20170658

21. Sujatha B, Manoj Kumar MG, Pratap Gowd MJ, et al. Ozone therapy a paradigm shift in dentistry. An Open Access Peer Reviewed E. J Health Sci 2013;2(3):1-10.

22. Bacchi S, Palumbo P, Sponta A, et al. Clinical pharmacology of non-steroidal anti-inflammatory drugs: a review. Antiinflamm Antiallergy Agents Med Chem 2012;11(1):52-64. DOI: 10.2174/187152312803476255

23. Slade GD, Foy SP, Shugars DA, et al. The impact of third molar symptoms, pain, and swelling on oral health-related quality of life. J Oral Maxillofac Surg 2004;62(9):1118-1124. DOI: 10.1016/j. joms.2003.11.014

24. Sukegawa S, Yokota K, Kanno T, et al. What are the risk factors for postoperative infections of third molar extraction surgery: a retrospective clinical study? Med Oral Patol Oral Cir Bucal 2019;24(1):e123-e129. DOI: 10.4317/medoral.22556

25. Lynch E. Evidence-based caries reversal using ozone. J Esthet Restor Dent 2008;20(4):218-222. DOI: 10.1111/j.1708-8240.2008.00183

26. Goyal M, Marya K, Jhamb A, et al. Comparative evaluation of surgical outcome after removal of impacted mandibular third molars using a Piezotome or a conventional handpiece: a prospective study. Br J Oral Maxillofac Surg 2012;50:556-561. DOI: 10.1016/j.bjoms.2011.10.010

27. Borle RM. Textbook of Oral and Maxillofacial Surgery. JP Medical Ltd. 2014.

28. Viebahn Haensler R. The Use of Ozone in Medicine. Heidelberg: Karl F, Haug Publishers 2002.

29. Kim K, Brar P, Jakubowski J, et al. The use of corticosteroids and nonsteroidal anti-inflammatory medication for the management of pain and inflammation after third molar surgery: a review of the literature. Oral Surg Oral Med Oral Pathol Oral Radiol Endod 2009;107:630. DOI: 10.1016/j.tripleo.2008.11.005

30. Markovic AB, Todorovic L. Post-operative analgesia after third molar surgery: contribution of the use of long-acting local anaesthetics, low-power laser, and diclofenac. Oral Surg Oral Med Oral Pathol Oral Radiol Endod 2006;102:4-8. DOI: 10.1016/j.tripleo.2006.02.024

31. Lago ML, Dinitz FM, Serna RC, et al. Relationships between surgical difficulty and post-operative pain in lower third molar extractions. J Oral Maxillofac Surg 2007;65:979-983. DOI: 10.1016/j. joms.2006.06.281

32. Markovic A, Todorovic L. Effectiveness of dexamethasone and low-power laser in minimizing oedema after third molar surgery: a clinical trial. Int J Oral Maxillofac Surg 2007; 36:226-229. DOI: 10.1016/j. ijom.2006.10.006 